\title{
Clinical and Radiological Results from Reconstruction of Massive Acetabular Defects Using 3D Printed Trabecular Titanium Implants
}

\author{
Johann Henckel ${ }^{1}$, Matthieu Durand-Hill ${ }^{1}$, Sabir Noory ${ }^{2}$, John Skinner ${ }^{2}$, Alister \\ Hart $^{1}$ \\ ${ }^{1}$ University College London, London, United Kingdom \\ ${ }^{2}$ Royal National Orthopaedic Hospital, London, United Kingdom
}

\begin{abstract}
Additive manufacturing has enabled a radical change in how surgeons reconstruct massive acetabular defects in revision hip surgery. We report on the early clinical and radiological results from our methods for surgical planning, design, and implantation of 3D printed trabecular titanium implants in a cohort of patients with large unclassifiable pelvic defects.

We set up a prospective investigation involving 7 consecutive patients. Inclusion criteria was the following: 1) A history of previous total hip replacement; and 2) Current imaging showing at least a Paprosky 3B defect. Planned acetabular inclination and version was $40^{\circ}$ and $20^{\circ}$ respectively. Post operatively all patients had a CT scan which was analysed with software to determine component position and compared to planned. Outpatient review was done at 2 weeks (For wound), 6 weeks (for weight bearing and fixation) and 52 weeks (for fixation and infection) post-operative.
\end{abstract}

3

The median age at surgery was: 65 years $(40-78)$. The median bone defect volume was $140 \mathrm{~cm}^{3}$. Median surgery length was 5.2 hours (3-6.25). Median blood loss was $1300 \mathrm{~mL}$ (450- 2000). Radiologically, components were stable and no screw breakages were identified. Achieved inclination was $41.0^{\circ}(29.0-$ 55.6) and achieved version was $15.8^{\circ}$ (3.8-43.6). Median Oxford Hip score improved from 9 (2-44) to $25(18-32)$.

We have demonstrated a new series of pre, intra and post-operative methods for reconstruction of unclassifiable acetabular bony defects. Initial clinical and radiological results are excellent considering the severity of the bony defects. We recommend the use of our or similar methods when trying to reconstruct these defects. 


\section{Introduction}

New 3D planning and implant printing technology has enabled a radical change in how surgeons reconstruct massive acetabular defects and pelvic discontinuity in revision hip surgery. With aging populations and a trend for hip replacements in younger patients the incidence of such defects is predicted to rise (1). Previously options available to patients with severe bone loss were limited to: bone grafts $(2,3)$, acetabular reconstruction rings (4), off the shelf Jumbo acetabular components (5), oblong acetabular components (6) and as a last resort, joint excision (7).

Additive manufacturing has enabled printing of patient specific implants in titanium to treat this unsolved clinical problem (1). We report on the early clinical results from our novel methods for surgical planning, design, and implantation in a cohort of patients with large unclassifiable pelvic defects (bone loss greater than Paproksy 3B) associated with failed total hip replacement.

\section{Methods}

We set up a prospective investigation involving 7 consecutive patients. Inclusion criteria was the following: 1) A history of previous total hip replacement; and 2) Current imaging showing at least a Paprosky 3B defect. The median age at surgery was: 65 years (40-78).

DICOM files obtained from CT were used to generate 3D models and for accurate assessment of local bone quality, volume of bone loss and the Centre of rotation (CoR) of the failed hip. Finite element modelling was used to determine optimum implant thickness and fixation to minimise stress shielding. Feasibility of reconstruction was determined by two experienced hip surgeons.

Collaboration between surgeons and engineers resulted in final design (Figure 1). The number of hours required to achieve this was recorded and the design process analysed. The 3 steps in design were: 1) Filling the defect with trabecular titanium; 2) Fixation of the pelvis using structural titanium and screw holes; and 3) Location of the CoR of the socket.

The key steps in surgery were: extensive posterior approach, involvement of a vascular surgeon and the use of an extra peritoneal approach to protect blood vessels; reaming of non-viable bone as per plan, trial with 3D printed plastic implant model, and fixation of titanium implants with screws using patient specific drill guides. 
1A)

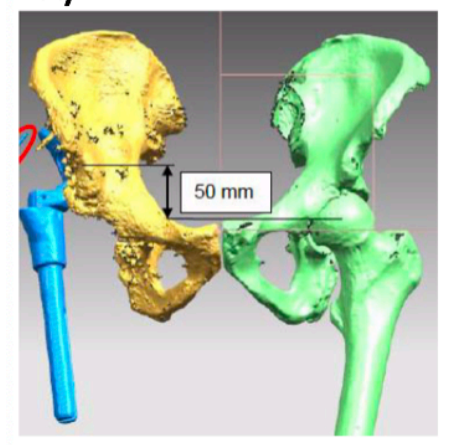

1B)

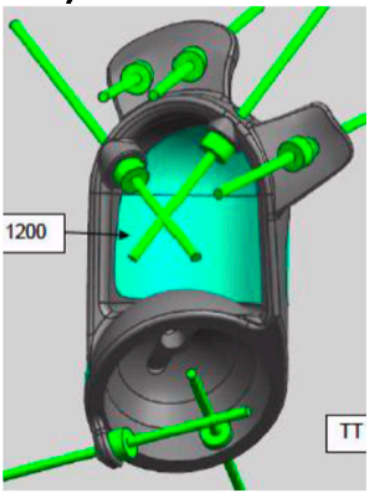

1C)

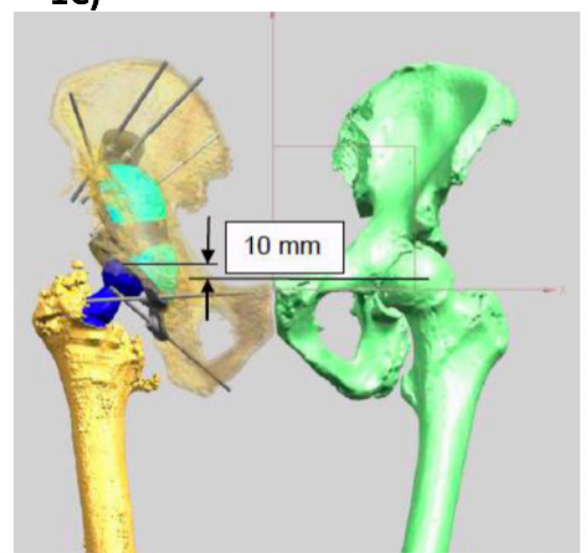

Figure 1. A) AP view of a 3D model generated from a preoperative CT scan of the patient's pelvis with proximal migration marked. B) Final component design c) Proposed component location.

Post-operatively all patients had a low dose CT scan which was analysed with software to determine the position of CoR and inclination and version angles of the socket in relation to the anterior pelvic plane. Physiotherapists specialising in hip rehabilitation used muscle co-ordination techniques typically employed for tumour reconstruction surgery e.g. slings and springs to help train the hip abductor muscles. Outpatient review was done at 2 weeks (For wound), 6 weeks (for weight bearing and fixation) and 52 weeks (for fixation and infection) post-operative.

\section{Results}

\subsection{Pre-operative}

The time required to generate the 3D pelvic models ranged from 2 to 5 hours. Characteristics of the patients' bone defects and location of the reconstructed CoR vs the mirrored contralateral are presented in Table 1.

Table 1. Pre-operative characteristics of patients

\begin{tabular}{|c|c|c|c|c|c|c|}
\hline Age & $\begin{array}{c}\text { Bone defect } \\
\text { volume } \\
\left(\mathrm{cm}^{3}\right)\end{array}$ & $\begin{array}{c}\text { CoR } \\
\text { proximal } \\
\text { Migration } \\
(\mathrm{mm})\end{array}$ & $\begin{array}{c}\text { Recon. } \\
\text { Change } \\
\text { CoR } \\
\text { Proximal/ } \\
\text { Distal }(\mathrm{mm})\end{array}$ & $\begin{array}{c}\text { Recon. } \\
\text { Change CoR } \\
\text { Anterior/ } \\
\text { Posterior } \\
\text { (mm) }\end{array}$ & $\begin{array}{c}\text { Recon. } \\
\text { Change CoR } \\
\text { Medial/ } \\
\text { Lateral }(\mathrm{mm})\end{array}$ & $\begin{array}{c}\text { Reconstructed } \\
\text { CoR vs } \\
\text { Contra- } \\
\text { lateral CoR } \\
(\mathrm{mm})\end{array}$ \\
\hline 63 & 167 & 39 & 36 & 8 & 9 & -3 \\
\hline 78 & 156 & 44 & 35 & 14 & 10 & -9 \\
\hline 49 & 140 & 31 & 31 & 5 & 6 & 0 \\
\hline 69 & 89 & 46 & 46 & 27 & 8 & 0 \\
\hline 61 & 148 & 26 & 26 & 12 & 20 & 0 \\
\hline 40 & 87 & 6 & 6 & 1 & 4 & 0 \\
\hline 67 & 175 & 35 & 35 & 7 & 13 & 0 \\
\hline
\end{tabular}




\subsection{Intra-operative}

All patients underwent a posterior approach, there were no intra-operative complications. Median surgery length was 5.2 hours $(3-6.25)$. Median blood loss during the operation was $1300 \mathrm{~mL}(450-$ 2000). Planned intra-operative inclination and version was 40 and 20 degrees respectively.

\subsection{Post-operative}

Post-operatively all patients' wounds healed well and no patients developed infections. All patients are mobilising independently. Median Oxford Hip score improved from 9 (2-44) to 25 (18-32). At the latest follow-up examination 1 patient reported dysaesthesia affecting the plantar aspect of their foot and great toe. Possible explanations for such symptoms include overstretching of the sciatic nerve or intraoperative irritation. Radiologically, components were stable and no screw breakages were identified. Achieved inclination was $41.0^{\circ}$ (29.0-55.6) and achieved version was $15.8^{\circ}(3.8-43.6)$.

\section{Discussion}

All eight patients in this series had complex acetabular defects (greater than Paprosky 3B). Traditional methods employed for joint reconstruction in such patients include: Oblong acetabular components, Bone grafts and Jumbo cups. Oblong acetabular components, while useful for small acetabular defects $(8,9)$, have high reported failure rates $(50 \%)$ in massive acetabular defects $(10)$. Furthermore, bone grafts are associated with premature failure, secondary to component loosening and allograph resorption $(2,3,11)$.

Our results of the 3D printed custom tri-flange component (PROMADEC, Lima corporate) have been promising. At an average of 18.6 weeks (6.29-41.4) weeks follow up none of the patients have required re-revision of their THR. Average oxford hip score has improved. Although one patient's oxford hip score has decreased, this patient is still in the early stages of post-operative recovery (6 weeks). In addition, the patient's revision operation was primarily conducted to address leg length discrepancy and patient quality of life. Both of which have improved post-operatively.

Limitations of our study include: a low sample size and short follow up period, however we will continue to follow and expand this cohort. In addition, future work will compare planned vs achieved screw position and achieved distal displacement of the Centre of rotation.

We have demonstrated a new series of pre, intra and post-operative methods to help solve the reconstruction of unclassifiable acetabular bony defects. Initial clinical and radiological results are excellent considering the severity of the bony defects. We recommend the use of our or similar methods when trying to reconstruct these defects.

\section{References}

1. Wyatt MC. Custom 3D-printed acetabular implants in hip surgery--innovative breakthrough or expensive bespoke upgrade? Hip Int. 2015;25(4):375-9.

2. Delloye C, Banse X, Brichard B, Docquier PL, Cornu O. Pelvic reconstruction with a structural pelvic allograft after resection of a malignant bone tumor. J Bone Joint Surg Am. 2007;89(3):579-87. 
3. Schreurs BW, Te Stroet MA, Rijnen WH, Gardeniers JW. Acetabular re-revision with impaction bone grafting and a cemented polyethylene cup; a biological option for successive reconstructions. Hip Int. 2015;25(1):44-9.

4. Rosson J, Schatzker J. The use of reinforcement rings to reconstruct deficient acetabula. J Bone Joint Surg Br. 1992;74(5):716-20.

5. Whaley AL, Berry DJ, Harmsen WS. Extra-large uncemented hemispherical acetabular components for revision total hip arthroplasty. J Bone Joint Surg Am. 2001;83-A(9):1352-7.

6. Chen WM, Engh CA, Jr., Hopper RH, Jr., McAuley JP, Engh CA. Acetabular revision with use of a bilobed component inserted without cement in patients who have acetabular bone-stock deficiency. J Bone Joint Surg Am. 2000;82(2):197-206.

7. Muller RT, Schlegel KF, Konermann H. Long-term results of the Girdlestone hip. Arch Orthop Trauma Surg. 1989;108(6):359-62.

8. Berry DJ, Sutherland CJ, Trousdale RT, Colwell CW, Jr., Chandler HP, Ayres D, et al. Bilobed oblong porous coated acetabular components in revision total hip arthroplasty. Clin Orthop Relat Res. 2000(371):154-60.

9. Dennis DA. Management of massive acetabular defects in revision total hip arthroplasty. $\mathbf{J}$ Arthroplasty. 2003;18(3 Suppl 1):121-5.

10. Sutherland CJ. Early experience with eccentric acetabular components in revision total hip arthroplasty. Am J Orthop (Belle Mead NJ). 1996;25(4):284-9.

11. Nieminen J, Pakarinen TK, Laitinen M. Orthopaedic reconstruction of complex pelvic bone defects. Evaluation of various treatment methods. Scand J Surg. 2013;102(1):36-41.

\section{Disclosures}

None 